\title{
TOLERÂNCIA DE CULTIVARES DE CANA-DE-AÇÚCAR A HERBICIDAS APLICADOS EM PÓS-EMERGÊNCIA $\left({ }^{1}\right)$
}

\author{
JOSEANE RODRIGUES DE SOUZA $\left({ }^{2}\right)$; DILERMANDO PERECIN $\left(3^{*}\right)$; \\ CARLOS ALBERTO MATHIAS AZANIA $\left({ }^{4}\right)$; ANA REGINA SCHIAVETTO $\left({ }^{5}\right)$; \\ IGOR VANZELA PIZZO $\left({ }^{6}\right)$; LILIAM SILVIA CANDIDO $\left({ }^{7}\right)$
}

\begin{abstract}
RESUMO
O presente trabalho teve por objetivo avaliar a tolerância de cultivares de cana-de-açúcar a herbicidas aplicados em pós-emergência inicial da soqueira. O experimento foi implantado em Ribeirão Preto (SP), no ano agrícola de 2007/2008. O delineamento experimental foi de blocos ao acaso, em esquema de parcelas subdivididas com 36 tratamentos em quatro repetições. Foram utilizadas as cultivares IACSP942094, IACSP94-2101, IACSP93-3046, IACSP94-4004, RB72454 e a IAC 86-2480 nas parcelas e os herbicidas, constituídos pela mistura pronta de diurom $\left(1170 \mathrm{~g} \mathrm{ha}^{-1}\right)+$ hexazinona $\left(330 \mathrm{~g} \mathrm{ha}^{-1}\right)$; diurom (1865 $\left.\mathrm{g} \mathrm{ha}^{-1}\right)$ + hexazinona (234 $\left.\mathrm{g} \mathrm{ha}^{-1}\right)$; metribuzim; tebutiuron; amicarbazona e uma testemunha nas subparcelas. Foram avaliados os sintomas visuais de intoxicação, teor relativo de clorofila, eficiência fotoquímica máxima do fotossistema II, altura, estande, qualidade tecnológica da cana e a produção dos colmos. Concluiu-se que as cultivares IACSP94-2094, IACSP94-2101, IACSP93-3046, IACSP94-4004, RB72454 e IAC862480 não foram influenciadas pelos herbicidas, apenas ocorreram diferenças inerentes à própria genética. Observou-se apenas leves sintomas de intoxicação na fase inicial de desenvolvimento e não se constatou nenhum prejuízo ao conteúdo de clorofila, avaliado pelo teor relativo de clorofila. No sistema fotossintético houve pequeno prejuízo na fase inicial, quando avaliado pela eficiência fotoquímica máxima do FS II $\left(\mathrm{F}_{\mathrm{v}} / \mathrm{F}_{\mathrm{m}}\right)$, mas que não foi suficiente para prejudicar a altura, o estande, a produção e a qualidade tecnológica das diferentes cultivares de cana-de-açúcar estudadas.
\end{abstract}

Palavras-chave: Saccharum spp., seletividade, sintomas de intoxicação, fitotoxicidade.

$\left({ }^{1}\right)$ Recebido para publicação em 8 de agosto de 2008 e aceito em 18 de junho de 2009.

( $\left.{ }^{2}\right)$ Parte da dissertação de mestrado. Programa de Genética e Melhoramento de Plantas - Universidade Estadual Paulista, Faculdade de Ciências Agrárias e Veterinárias, 14849-900, Jaboticabal (SP). E-mail: joseaneagro@yahoo.com.br

$\left({ }^{3}\right)$ Departamento de Ciências Exatas, Universidade Estadual Paulista, Faculdade de Ciências Agrárias e Veterinárias, 14849-900 Jaboticabal (SP). E-mail: perecin@fcav.unesp.br $(*)$ Autor correspondente. Bolsista CNPq.

$\left({ }^{4}\right)$ Instituto Agronômico, Centro de Cana, Caixa Postal 206, 14001-970 Ribeirão Preto (SP). E-mail: azania@iac.sp.gov.br

$\left({ }^{5}\right)$ Mestranda em Agronomia - Genética e Melhoramento de Plantas, Universidade Estadual Paulista, Faculdade de Ciências Agrárias e Veterinárias, 14849-900 Jaboticabal (SP). E-mail: ana.schiavetto@hotmail.com

$\left({ }^{6}\right)$ Graduando em Agronomia, Centro Universitário Moura Lacerda, Estagiário de iniciação científica, IAC/Centro Cana, Ribeirão Preto (SP). E-mail: igorpizzo@hotmail.com

(7) Doutoranda em Agronomia - Genética e Melhoramento de Plantas, Universidade Estadual Paulista, Faculdade de Ciências Agrárias e Veterinárias, Jaboticabal (SP). E-mail: bioliliam@yahoo.com.br 


\title{
ABSTRACT \\ TOLERANCE OF SUGARCANE CULTIVARS TO HERBICIDES APPLIED IN POST-EMERGENCE
}

\begin{abstract}
This study aimed to assess the tolerance of cultivars of sugarcane to herbicides applied in postemergence initial of ratoon. The experiment was carried in Ribeirão Preto, SP, Brazil, in the agricultural year $2007 / 2008$. The experimental design was the randomized blocks, in split-plots, 36 treatments and four replications. It was used the cultivars IACSP94-2094, IACSP94-2101, IACSP93-3046, IACSP94-4004, RB72454 and IAC86-2480 in plots and herbicides, were made by mixture ready to diuron $\left(1170 \mathrm{~g} \mathrm{ha}^{-1}\right)+$ hexazinone (330 $\left.\mathrm{g} \mathrm{ha}^{-1}\right)$; diuron $\left(1865 \mathrm{~g} \mathrm{ha}^{-1}\right)+$ hexazinone $\left(234 \mathrm{~g} \mathrm{ha}^{-1}\right)$; metribuzin; tebuthiuron; amicarbazone and a control in the sub-plots. The intoxication symptoms of visual, relative content of chlorophyll and photochemical efficiency of PS II, height, stand, technological quality of sugarcane and production the culms. It was concluded the cultivars IACSP94-2094, IACSP94-2101, IACSP93-3046, IACSP944004, RB72454 and IAC86-2480 were not affected by herbicides, only showed differences inherent in the genetics. In all cultivars, there was only mild intoxication symptoms of visual at the initial stage of development and there was not any damage to the content of chlorophyll, measured by relative content chlorophyll. The photosynthetic system showed little damage in the initial phase, when measured by the photochemical efficiency of PS II $\left(\mathrm{F}_{\mathrm{v}} / \mathrm{F}_{\mathrm{m}}\right)$, but that was not enough to constrain the height, stand, production and technology quality of different cultivars of sugarcane studied.
\end{abstract}

Key words: Saccharum spp., selectivity, intoxication symptoms, phytotoxicity.

\section{INTRODUÇÃO}

A cultura da cana-de-açúcar destaca-se dentre as mais cultivadas no Brasil em função da matériaprima que é fornecida para a indústria sucroalcooleira. Para a safra 2008/2009, a estimativa para produção na Região Centro-Sul, que concentra $86 \%$ da produção nacional de cana moída, é de 498,1 milhões de toneladas, representando um crescimento de $16 \%$ em relação à safra 2007/2008 (UNICA, 2008). Todavia a produtividade da cana-de-açúcar é negativamente afetada, dentre outros fatores, pela presença de plantas daninhas (GRACIANO e RAMALHO, 1983) e dentre as estratégias de manejo está a utilização de herbicidas. Atualmente, os produtos registrados são seletivos às plantas de cana-de-açúcar (AZANiA e AZANiA, 2005), mas a tolerância às moléculas desses herbicidas é específica para cada cultivar (AZANIA et al., 2008).

Entende-se por seletividade a capacidade de um determinado herbicida em eliminar as plantas daninhas de uma cultura, sem reduzir a produtividade e a qualidade do produto de interesse econômico (NEGRIsoli et al., 2004). Quando o objetivo for avaliar os efeitos de herbicidas sobre a cana-deaçúcar, é fundamental que, além de avaliar as injúrias provocadas por eles, seja avaliada também a taxa de crescimento e a produtividade da cultura (VelinI et al., 2000). A seletividade é indicada pelas empresas de herbicidas a partir de ensaios, os quais procuram testar os novos herbicidas comparativamente com aqueles cujos efeitos são sabidamente conhecidos (AzANIA et al., 2005a).
Segundo Velini et al. (1993), a cultura da cana-de-açúcar pode ter até $27 \%$ de comprometimento da sua área foliar sem que a produtividade seja prejudicada, e essas injúrias também podem ser devidas ao uso inadequado de herbicidas ou pela pouca tolerância da cultivar. Rolim e CHRISTOFFoleti (1982) relataram que as cultivares de cana-de-açúcar podem ter características morfológicas e fisiológicas distintas, sendo provável que ocorram alterações quanto à tolerância a herbicidas específicos. FERREIRA et al. (2005) observaram que as cultivares de cana-deaçúcar têm apresentado respostas diferenciadas aos herbicidas, tendo como consequências frequentes problemas de fitotoxicidade, podendo ocasionar redução na produtividade do canavial. Dessa forma, avaliar o efeito do manejo para cada cultivar de canade-açúcar e também a tolerância aos herbicidas é uma questão a ser considerada nos Programas de Melhoramento Genético da cultura.

Na cultura da cana-de-açúcar para aferir os prejuízos causados pelos herbicidas é comum avaliar visualmente as cloroses, necroses e amarelecimento nas folhas da cultura, a exemplo do estudo realizado por MACIEL et al. (2008), que constataram sintomas de intoxicação inferiores a $20 \%$ ao estudarem a cultivar SP 801842 até aos 63 dias após aplicação de hexazinona+diurom. Essas avaliações são necessárias porque a maioria dos herbicidas utilizados em cana-de-açúcar possui como mecanismo de ação a inibição da fotossíntese, seja pela redução do conteúdo de clorofila (SALLA et al., 2007; AzAnia et al., 2005b) seja por redução da atividade fotoquímica (MAPA, 2009; Azania et al., 2005b, 2006; CECHIN, 1996). 
A altura, estande, massa e qualidade dos colmos são também variáveis que podem ser prejudicadas pelos herbicidas e comumente avaliadas nos ensaios de seletividade. Nesse sentido, observouse redução no número de colmos devido ao uso de tebutiurom e metribuzim, que também diminuiu a altura das plantas (NeGRIsOli et al., 2004) e diminuição na massa dos colmos e nos sólidos solúveis por ambos os herbicidas (BARELLA e ChristofFoleti, 2006).

Esse estudo objetivou avaliar a tolerância de diferentes cultivares de cana-de-açúcar aos herbicidas aplicados em pós-emergência inicial da soqueira avaliando o desenvolvimento das plantas, as características relacionadas à qualidade da matériaprima e a produção final da cultura.

\section{MATERIAL E MÉTODOS}

O trabalho foi desenvolvido no município de Ribeirão Preto (SP), em soqueira de segundo corte, entre setembro de 2007 a junho de 2008 . O solo da área experimental foi classificado como Latossolo Vermelho Escuro com $61,2 \%$ de argila, 22,2\% de silte e $16,6 \%$ de areia na camada arável. Após a colheita da primeira soqueira, ocorrida em 10 de julho de 2007, foi realizada a adubação da área experimental com a formulação 20-5-15 (500 kg ha-1).

O delineamento experimental foi o de blocos ao acaso em esquema de parcelas subdivididas, com 36 tratamentos em quatro repetições. As cultivares foram alocadas nas parcelas e os herbicidas e a testemunha nas subparcelas. As parcelas foram constituídas de cinco linhas de cana-de-açúcar de 60 $\mathrm{m} \times 1,50 \mathrm{~m}\left(450 \mathrm{~m}^{2}\right)$ e as subparcelas por cinco linhas de $8 \mathrm{~m} \times 1,50 \mathrm{~m}\left(60 \mathrm{~m}^{2}\right)$. Em cada subparcela, as três linhas centrais foram consideradas como área útil (36 $\mathrm{m}^{2}$ ) para a avaliação das variáveis analisadas.

Foram utilizadas as cultivares IACSP942094, IACSP94-2101, IACSP93-3046, IACSP94-4004, RB72454 e a IAC86-2480. As quatro primeiras foram escolhidas devido ao recente lançamento em 2005 (LANDEll et al., 2005) e, portanto há pouca informação a respeito da tolerância a herbicidas; a variedade RB72454 é cultivada em grande parte dos canaviais, e a IAC86-2480, por ser uma variedade forrageira (LANDELL et al., 2002), é amplamente difundida. Os herbicidas foram constituídos pela mistura pronta de diurom+hexazinona (1170 $\mathrm{g} \mathrm{ha}^{-1}$ +330 $\left.\mathrm{g} \mathrm{ha}^{-1}\right)$; diurom+hexazinona (1865 $\mathrm{g} \mathrm{ha}^{-1}+$ $\left.234 \mathrm{~g} \mathrm{ha}^{-1}\right)$; metribuzin (2400 $\left.\mathrm{g} \mathrm{ha}^{-1}\right)$; tebutiurom (1200 $\mathrm{g} \mathrm{ha}^{-1}$ ) e amicarbazona (1260 $\mathrm{g} \mathrm{ha}^{-1}$ ) e uma testemunha sem aplicação de herbicidas. Os herbicidas estudados, segundo Rodrigues e Almeida (2005), possuem como mecanismo de ação a inibição da fotossíntese, especificamente no fotossistema II.

Os herbicidas foram aplicados em 20/9/ 2007, em pós-emergência inicial da cultura (fase de formação do esporão) e pré-emergência das plantas daninhas. Foi utilizado pulverizador costal pressurizado com barra de quatro pontas (jato leque 11002), espaçadas de $50 \mathrm{~cm}$, a uma pressão de $30 \mathrm{lb} \mathrm{pol}^{-2}$, sendo empregado volume de calda correspondente a $250 \mathrm{~L} \mathrm{ha}^{-1}$. No momento das aplicações, entre $16 \mathrm{~h}$ e 19 horas, a velocidade do vento oscilou entre 3 e $5 \mathrm{~km} \mathrm{~h}^{-1}$, a umidade média relativa do ar e a temperatura média, foram de $41 \%$ e $30{ }^{\circ} \mathrm{C}$ respectivamente.

A tolerância das cultivares de cana-deaçúcar aos herbicidas foi avaliada aos 15,30 e 60 dias após a aplicação (DAA), realizando-se avaliações de sintomas visuais de intoxicação, teor relativo de clorofila e a eficiência fotoquímica máxima do FS II das plantas. Os sintomas visuais de intoxicação foram avaliados com uso de uma escala percentual de notas variando entre 0 (zero) e 100 (cem), em que 0 corresponde à ausência de quaisquer injúrias e cem a morte das plantas. $\mathrm{O}$ teor relativo de clorofila foi determinado com clorofilômetro (SPAD 502 Minolta). A eficiência fotoquímica máxima do FS II dada pela razão $F_{v} /$ $F_{m}\left(F_{v}\right.$ é a fluorescência variável e $F_{m}$ é a fluorescência máxima) foi determinada com fluorômetro (PEA - Plant Efficiency Analyser, Hansatech), com tempo de adaptação ao escuro de 20 minutos. Essas avaliações foram realizadas no período da manhã, no terço médio da folha +3 de seis plantas escolhidas ao acaso em cada subparcela.

Foram realizadas também avaliações de altura $(\mathrm{cm})$ de dez plantas escolhidas ao acaso, medindo-se à distância do solo até o ápice da primeira folha completamente desenvolvida aos 30 , 60, 90 e 180 DAA e estande (colmos $\mathrm{m}^{-1}$ ), sendo contados todos os colmos em três linhas de $8 \mathrm{~m}$ de comprimento na área útil de cada subparcela aos 30, 90 e 180 DAA.

Por ocasião da colheita, ocorrida em 18 de junho de 2008, a soqueira estava com 330 dias de ciclo, sendo avaliada a produção de colmos $\left(t h^{-1}\right)$ e a qualidade tecnológica da cana. A produção foi obtida a partir da coleta e pesagem de 30 colmos, sendo esses retirados seqüencialmente em número de 10 em cada uma das três linhas centrais de cada subparcela, originando, assim, três feixes contendo 10 colmos cada um. Foram pesados com o auxílio de uma célula de carga com precisão de $50 \mathrm{~g}$, modelo WT 3000. 
A qualidade tecnológica da cana foi avaliada a partir da coleta de dez colmos retirados da linha central de cada subparcela, sendo analisados os sólidos solúveis totais no caldo $\left({ }^{\circ}\right.$ Brix) e o teor de sacarose aparente $(\%)$ e, posteriormente, calculados a pureza (\%), os açúcares redutores (AR) no caldo, o açúcar total recuperado ( $\mathrm{kg}$ açúcar $\mathrm{t} \mathrm{cana}^{-1}$ ) e a fibra (\%) na cana, segundo as recomendações do CONSECANA (2006).

Foi realizada a análise de variância (teste F) e os contrastes de interesse dentro de cada cultivar segundo Pimentel Gomes (2000). Os contrastes considerados foram: 1) testemunhas versus tratados, compara a média do tratamento sem herbicida com os que têm herbicida (com 1 grau de liberdade); 2 ) entre tratamentos com herbicida, compara a igualdade do efeito dos herbicidas em cada cultivar (com 4 graus de liberdade). Para auxiliar na visualização das diferenças entre médias dentro de cada cultivar são apresentados os valores de diferença mínima significativa (dms) pelo teste de Tukey.

\section{RESULTADOS E DISCUSSÃO}

Em relação à fitotoxicidade, foram observados leves sintomas de intoxicação em todas as cultivares que receberam os tratamentos com herbicidas, aos 15 e 30 DAA sendo estes sintomas caracterizados por um leve amarelecimento nas folhas das plantas acompanhado de secamento nas pontas (Tabela 1). Segundo informações de RoDRIGUES e ALMEIDA (2005), os produtos utilizados são inibidores do fotossistema II e interferem no processo fotossintético das plantas; assim, é comum observar amarelecimento das folhas, especialmente nos primeiros dias após aplicação dos herbicidas. Christoffoleti (1997) comentou que esses herbicidas interferem na membrana do cloroplasto, local onde ocorre a fase luminosa da fotossíntese, impedindo o transporte de elétrons e consequentemente a formação de ATP.

Os leves sintomas de intoxicação, observados aos 15 DAA ocorreram quando as plantas foram tratadas com a mistura pronta diurom +hexazinona formulados com (1170 $\mathrm{g}$ ha $\left.{ }^{1}+330 \mathrm{~g} \mathrm{ha}^{-1}\right)$, que provavelmente interferiu nas plantas inibindo a atividade fotoquímica (Oliveira Junior, 2001a). Azania et al. (2005b, 2006), em estudos com a cultivar RB835089, em pós-emergência inicial e tardia das plantas de cana-de-açúcar na época das chuvas e na estiagem em soqueira de terceiro e quarto cortes, respectivamente, observaram sintomas similares quando as plantas foram tratadas com a mistura pronta diurom+hexazinona $\left(1170 \mathrm{~g} \mathrm{ha}^{-1}+330 \mathrm{~g}\right.$ $\left.\mathrm{ha}^{-1}\right)$.
Aos 60 DAA, constatou-se redução das injúrias causadas pelos herbicidas e recuperação satisfatória da cultura, exceto na cultivar IACSP933046 em que ainda havia injúrias próximas a 10\%, tidas na prática como leves. A recuperação da cultura pode estar relacionada com as condições climáticas devido ao aumento da temperatura e à ocorrência das chuvas (Tabela 2), que se intensificaram nos primeiros 60 DAA. Nesse período, o metabolismo das plantas da cultura pôde ficar mais intenso possibilitando maior desenvolvimento das plantas de cana-de-açúcar que, possivelmente, conseguiram destoxificar-se das moléculas dos herbicidas, consequentemente refletindo na diminuição dos sintomas de intoxicação.

Entretanto, a partir dessa ocasião não se observou mais sintomas de intoxicação nas plantas de cana-de-açúcar. A umidade no solo, oriunda das chuvas, e a elevação da temperatura certamente propiciaram a degradação das moléculas herbicidas no solo, pois segundo Rodrigues e Almeida (2005), a degradação das moléculas no solo é dada principalmente pela flora microbiana e/ou elevação da temperatura.

Segundo Oliveira Junior (2001b), a destoxificação dos herbicidas no metabolismo das plantas pode ocorrer devido à produção de enzimas, que metabolizam a molécula herbicida. O autor também comenta que uma única enzima pode possuir característica de ampla especificidade, conferindo a uma espécie metabolizar e destoxificar-se de diferentes herbicidas. Possivelmente, variações na genética das diferentes cultivares de cana-de-açúcar podem ter induzido diferentes efeitos dos herbicidas nas plantas o que tem sido fator importante na tolerância de cultivares a herbicidas (FERREIRA et al., 2005).

Entretanto, mesmo ocorrendo amarelecimento nas plantas de cana-de-açúcar, os herbicidas não comprometeram o teor relativo de clorofila aos 60 DAA (Tabela 3). As variações no teor de clorofila ocorreram em função das cultivares, sendo esse efeito significativo em todas as épocas avaliadas (Tabela 3 ). Esses resultados indicam ser o teor relativo de clorofila predominantemente um atributo genético das cultivares em estudo, e que não foi influenciado pelos herbicidas testados.

Em relação à eficiência fotoquímica máxima do FS II $\left(\mathrm{F}_{\mathrm{v}} / \mathrm{F}_{\mathrm{m}}\right)$, houve efeito da interação entre cultivares e herbicidas aos 15 DAA e entre herbicidas aos 60 DAA (Tabela 3). Os valores médios da eficiência fotoquímica máxima do FS II $\left(\mathrm{F}_{\mathrm{v}} / \mathrm{F}_{\mathrm{m}}\right)$ para as cultivares foi da ordem de 0,70 a 0,$75 ; 0,75$ a 0,77 e 0,63 a 0,72 aos 15,30 e 60 DAA, respectivamente, (Tabela 3). 
Tabela 1. Notas dos sintomas visuais de intoxicação das seis cultivares de cana-de-açúcar proporcionados por herbicidas aos 15, 30 e 60 DAA (dias após aplicação).

\begin{tabular}{|c|c|c|c|c|}
\hline \multirow{2}{*}{ Cultivares } & \multirow{2}{*}{ Herbicidas $\left({ }^{1}\right)$} & \multicolumn{3}{|c|}{ Avaliações (DAA) } \\
\hline & & 15 & 30 & 60 \\
\hline \multirow{6}{*}{ IACSP94-2094 (A) } & testemunha & 0,00 & 0,00 & 0,00 \\
\hline & diurom + hexazinona & 11,25 & 10,00 & 0,00 \\
\hline & diurom + hexazinona* & 11,25 & 12,50 & 7,50 \\
\hline & metribuzin & 10,00 & 10,00 & 0,00 \\
\hline & tebuthiuron & 10,00 & 10,00 & 0,00 \\
\hline & amicarbazona & 10,00 & 10,00 & 2,50 \\
\hline \multirow{6}{*}{ IACSP94-2101(B) } & testemunha & 0,00 & 0,00 & 0,00 \\
\hline & diurom + hexazinona & 17,50 & 12,50 & 0,00 \\
\hline & diurom + hexazinona* & 12,50 & 10,00 & 5,00 \\
\hline & metribuzin & 10,00 & 15,00 & 0,00 \\
\hline & tebuthiuron & 10,00 & 15,00 & 2,50 \\
\hline & amicarbazona & 17,50 & 12,50 & 2,50 \\
\hline \multirow{6}{*}{ IACSP93-3046 (C) } & testemunha & 0,00 & 0,00 & 0,00 \\
\hline & diurom + hexazinona & 12,50 & 12,50 & 7,50 \\
\hline & diurom + hexazinona* & 10,00 & 12,50 & 10,00 \\
\hline & metribuzin & 10,00 & 12,50 & 0,00 \\
\hline & tebuthiuron & 12,50 & 15,00 & 5,00 \\
\hline & amicarbazona & 10,00 & 10,00 & 7,50 \\
\hline \multirow{6}{*}{ IACSP94-4004 (D) } & testemunha & 0,00 & 0,00 & 0,00 \\
\hline & diurom + hexazinona & 15,00 & 10,00 & 2,50 \\
\hline & diurom + hexazinona* & 10,00 & 10,00 & 0,00 \\
\hline & metribuzin & 10,00 & 12,50 & 0,00 \\
\hline & tebuthiuron & 7,50 & 10,00 & 0,00 \\
\hline & amicarbazona & 10,00 & 12,50 & 2,50 \\
\hline \multirow{6}{*}{ RB72454 (E) } & testemunha & 0,00 & 0,00 & 0,00 \\
\hline & diurom + hexazinona & 12,50 & 12,50 & 2,50 \\
\hline & diurom + hexazinona* & 10,00 & 10,00 & 0,00 \\
\hline & metribuzin & 10,00 & 10,00 & 0,00 \\
\hline & tebuthiuron & 10,00 & 10,00 & 2,50 \\
\hline & amicarbazona & 10,00 & 10,00 & 2,50 \\
\hline \multirow{23}{*}{ IAC $86-2480(\mathrm{~F})$} & testemunha & 0,00 & 0,00 & 0,00 \\
\hline & diurom + hexazinona & 10,00 & 10,00 & 0,00 \\
\hline & diurom + hexazinona* & 11,25 & 10,00 & 0,00 \\
\hline & metribuzin & 7,50 & 10,00 & 0,00 \\
\hline & tebuthiuron & 10,00 & 10,00 & 0,00 \\
\hline & amicarbazona & 10,00 & 12,50 & 0,00 \\
\hline & $\operatorname{dms}\left({ }^{2}\right)$ & 5,44 & 6,41 & 9,34 \\
\hline & CV (\%) & 28,97 & 33,01 & 261,44 \\
\hline & F (cult) & $4,07^{*}$ & $2,17^{\mathrm{ns}}$ & $3,43^{*}$ \\
\hline & $\mathrm{F}$ (herb) & $73,81^{*}$ & $53,09 *$ & $2,70 *$ \\
\hline & F (cult*herb) & $1,62^{*}$ & $0,90^{\mathrm{ns}}$ & $0,79^{\mathrm{ns}}$ \\
\hline & F (test vs herb em A) & $52,48^{*}$ & $37,80^{*}$ & $0,65^{\mathrm{ns}}$ \\
\hline & F (test vs herb em B) & $86,76^{*}$ & $57,94^{*}$ & $0,65^{\mathrm{ns}}$ \\
\hline & F (test vs herb em C) & $57,60^{*}$ & $53,57^{*}$ & $5,82 *$ \\
\hline & F (test vs herb em D) & $52,48^{*}$ & $41,49^{*}$ & $0,16^{\mathrm{ns}}$ \\
\hline & F (test vs herb em E) & $52,48^{*}$ & $37,80 *$ & $0,36^{\mathrm{ns}}$ \\
\hline & F (test vs herb em F) & $45,25^{*}$ & $37,80 *$ & $0,00^{\text {ns }}$ \\
\hline & F (entre herb A) & $0,22^{\mathrm{ns}}$ & $0,43^{\mathrm{ns}}$ & $1,72^{\mathrm{ns}}$ \\
\hline & $\mathrm{F}$ (entre herb B) & $6,84^{*}$ & $1,50^{\text {ns }}$ & $0,71^{\mathrm{ns}}$ \\
\hline & $\mathrm{F}$ (entre herb C) & $0,89^{\text {ns }}$ & $1,07^{\mathrm{ns}}$ & $2,33^{\text {ns }}$ \\
\hline & F (entre herb D) & $3,57^{*}$ & $0,64^{\mathrm{ns}}$ & $0,30^{\text {ns }}$ \\
\hline & $\mathrm{F}($ entre herb E) & $0,60^{\text {ns }}$ & $0,43^{\text {ns }}$ & $0,30^{\text {ns }}$ \\
\hline & $\mathrm{F}$ (entre herb F) & $0,89^{\text {ns }}$ & $0,43^{\text {ns }}$ & $0,00^{\text {ns }}$ \\
\hline
\end{tabular}

$\left({ }^{1}\right)$ diurom+hexazinona (1170 $\left.\mathrm{g} \mathrm{ha}^{-1}+330 \mathrm{~g} \mathrm{ha}^{-1}\right)$; diurom+hexazinona * $\left(1865 \mathrm{~g} \mathrm{ha}^{-1}+234 \mathrm{~g} \mathrm{ha}^{-1}\right)$; metribuzin (2400 g ha $\left.{ }^{-1}\right)$; tebuthiuron $\left(1200 \mathrm{~g} \mathrm{ha}^{-1}\right)$ e amicarbazona $\left(1260 \mathrm{~g} \mathrm{ha}^{-1}\right) \cdot\left({ }^{2}\right) \mathrm{dms}=$ diferença mínima significativa dentro de cultivar a $5 \%$ de probabilidade; $\mathrm{CV}=$ coeficiente de variação. 
Tabela 2. Precipitação pluvial (total mensal) e temperaturas médias mensais ocorridas durante o período do experimento $(2007 / 2008)$

\begin{tabular}{lcc}
\hline Mês & Precipitação & Temperatura \\
\hline & $\mathrm{mm}$ & ${ }^{\circ} \mathrm{C}$ \\
Setembro & 3,00 & 24,90 \\
Outubro & 49,40 & 26,10 \\
Novembro & 125,40 & 23,90 \\
Dezembro & 179,60 & 25,20 \\
Janeiro & 364,60 & 24,00 \\
Fevereiro & 197,20 & 24,50 \\
Março & 201,90 & 23,70 \\
Abril & 119,20 & 22,80 \\
Maio & 50,50 & 19,70 \\
Junho & 3,00 & 20,20 \\
\hline
\end{tabular}

Fonte: IAC/CIIAGRO.

De acordo com RiBEIRo et al. (2004), os valores de $F_{v} / F_{m}$ podem variar de 0,75 a 0,85 . CECHIN (1996) relatou que a eficiência fotoquímica máxima do FS II para a maioria das culturas é de 0,8 . Segundo o autor, valores inferiores podem provocar redução no fluxo de elétrons no fotossistema II com consequente redução na quantidade de energia disponibilizada para a fixação de $\mathrm{CO}_{2}$.

Assim, comparativamente, constatou-se que a eficiência fotoquímica máxima do FS II aos 60 DAA foi significativamente prejudicada, dado pelos valores inferiores a 0,72. Nessa ocasião, observaram-se menores médias para todas as cultivares em todos os tratamentos, inclusive a testemunha, especialmente quando as plantas foram tratadas com o herbicida amicarbazona, provavelmente o menos seletivo entre os herbicidas. Esses resultados podem estar associados às condições de chuva e temperaturas, registrados no fim de novembro de 2007 (Tabela 2), ocasião dos 60 DAA. Observou-se que a quantidade de chuvas nos primeiros $60 \mathrm{DAA}$ (setembro a novembro) foi abaixo do esperado. Portanto, pode-se inferir que a disponibilidade de água no solo não foi suficiente para as cultivares expressarem todo o potencial de crescimento, prejudicando inclusive a eficiência fotoquímica máxima do FS II. Além desse aspecto, cada cultivar responde de forma diferenciada às condições climáticas, devido às suas características genéticas o que justifica a variação observada entre as cultivares.

Entretanto, nos tratamentos com amicarbazona a variável foi ainda mais prejudicada, pois a água das chuvas possivelmente tenha sido suficiente para interferir sobre a solubilidade deste herbicida no solo. Este fato deve estar associado à solubilidade elevada em água, pois a molécula possui $460 \mathrm{ppm}$ à temperatura de $25^{\circ} \mathrm{C}$, em pH variando entre 4 e 9 (CARBONARI, 2007). Essa característica possivelmente possibilitou a maior absorção do herbicida pelas plantas, proporcionado os prejuízos observados aos 60 DAA. CATUnDA et al. (2005) também verificaram queda na eficiência fotossintética máxima do FS II em plantas de abacaxi quando avaliaram a interferência do herbicida amicarbazona.

As variáveis altura e estande também podem ser prejudicadas pelos herbicidas, mas os resultados indicaram diferenças significativas somente para o efeito de cultivares, com as maiores médias de altura observadas nas cultivares IACSP94-2101, IACSP942094 e RB72454 em todas as épocas avaliadas. Para o estande também foi constatada maior média na cultivar IACSP94-2094 aos 30 e 180 DAA e na IACSP93-3046 aos 90 DAA (Tabela 4). Observouse nas datas de avaliações, ausência do efeito de herbicidas e da interação entre cultivares e herbicidas. Provavelmente, as cultivares foram tolerantes aos herbicidas, evidenciando que as injúrias visuais e o prejuízo sobre a eficiência fotoquímica máxima do FS II causada por amicarbazona aos 60 DAA não foram suficientes para prejudicarem significativamente a altura e o estande.

FAGLIARI et al. (2001) também não observaram prejuízos à altura quando estudou a seletividade de metribuzim na cultivar RB 835089. AzANIA et al. (2001) também observaram leves injúrias, mas sem prejuízo à altura e ao estande avaliados até aos 180 DAA, quando estudaram a seletividade de tebutiurom, imazapic e imazapyr sobre a cultivar RB 835089.

No fim do ciclo da cultura, a produção e a qualidade tecnológica apenas revelaram efeito de cultivares e ausência de efeitos de herbicidas e da interação entre cultivares e herbicidas (Tabela 5). Assim, as cultivares IACSP94-4004, IACSP93-3046, IAC86-2480, RB72454, IACSP94-2101, IACSP94-2094 podem ser classificadas em ordem decrescente de produção.

Observando diferenças estatísticas apenas para o efeito cultivar, pode-se inferir que todos os herbicidas utilizados são seletivos para a cultura da cana-de-açúcar e que as diferenças observadas foram em função das características das cultivares. Os dados corroboram com aqueles de Rolim e Chistoffoleti (1982) quando avaliaram a tolerância de cultivares de cana-de-açúcar ao herbicida tebutiurom. 
Tabela 3. Teor relativo de clorofila e eficiência fotoquímica máxima do FS II $\left(F_{v} / F_{m}\right)$ das seis cultivares de cana-deaçúcar obtidos aos 15, 30 e 60 DAA (dias após aplicação)

\begin{tabular}{|c|c|c|c|c|c|c|c|}
\hline \multirow{3}{*}{ Cultivares } & \multirow{3}{*}{ Herbicidas $\left({ }^{1}\right)$} & \multicolumn{3}{|c|}{$\begin{array}{c}\text { Teor relativo } \\
\text { de clorofila (SPAD) }\end{array}$} & \multicolumn{3}{|c|}{$\begin{array}{l}\text { Eficiência fotoquímica } \\
\text { máxima do FS II (Fv/Fm) }\end{array}$} \\
\hline & & \multicolumn{3}{|c|}{ Avaliações (DAA) } & \multicolumn{3}{|c|}{ Avaliações (DAA) } \\
\hline & & 15 & 30 & 60 & 15 & 30 & 60 \\
\hline & testemunha & 32,91 & 32,82 & 42,43 & 0,75 & 0,77 & 0,71 \\
\hline & diurom + hexazinona & 33,88 & 36,58 & 44,18 & 0,74 & 0,77 & 0,70 \\
\hline \multirow[t]{6}{*}{ IACSP94-2094 (A) } & diurom + hexazinona * & 36,27 & 37,74 & 42,49 & 0,71 & 0,78 & 0,69 \\
\hline & metribuzin & 36,02 & 34,46 & 43,52 & 0,74 & 0,76 & 0,72 \\
\hline & tebuthiuron & 34,04 & 36,55 & 41,78 & 0,74 & 0,77 & 0,71 \\
\hline & amicarbazona & 34,90 & 35,59 & 42,49 & 0,73 & 0,76 & 0,62 \\
\hline & testemunha & 32,90 & 31,91 & 38,19 & 0,71 & 0,76 & 0,69 \\
\hline & diurom + hexazinona & 33,47 & 31,33 & 38,81 & 0,72 & 0,76 & 0,66 \\
\hline \multirow[t]{6}{*}{ IACSP94-2101(B) } & diurom + hexazinona * & 32,31 & 31,49 & 38,52 & 0,69 & 0,75 & 0,67 \\
\hline & metribuzin & 33,07 & 31,27 & 38,71 & 0,70 & 0,75 & 0,70 \\
\hline & tebuthiuron & 31,00 & 28,07 & 38,10 & 0,71 & 0,76 & 0,68 \\
\hline & amicarbazona & 30,24 & 31,14 & 38,65 & 0,74 & 0,75 & 0,57 \\
\hline & testemunha & 37,70 & 34,06 & 41,62 & 0,72 & 0,76 & 0,69 \\
\hline & diurom + hexazinona & 35,26 & 31,55 & 42,33 & 0,71 & 0,76 & 0,69 \\
\hline \multirow[t]{6}{*}{ IACSP93-3046 (C) } & diurom + hexazinona $*$ & 34,45 & 31,38 & 40,88 & 0,73 & 0,76 & 0,69 \\
\hline & metribuzin & 35,47 & 35,91 & 41,75 & 0,71 & 0,76 & 0,70 \\
\hline & tebuthiuron & 32,94 & 36,71 & 43,40 & 0,74 & 0,76 & 0,70 \\
\hline & amicarbazona & 32,03 & 34,40 & 42,39 & 0,70 & 0,76 & 0,63 \\
\hline & testemunha & 35,73 & 35,25 & 41,25 & 0,72 & 0,76 & 0,74 \\
\hline & diurom + hexazinona & 35,84 & 35,77 & 43,65 & 0,73 & 0,76 & 0,72 \\
\hline \multirow[t]{6}{*}{ IACSP94-4004 (D) } & diurom + hexazinona * & 35,26 & 36,40 & 41,95 & 0,72 & 0,76 & 0,72 \\
\hline & metribuzin & 36,18 & 36,03 & 41,91 & 0,73 & 0,76 & 0,72 \\
\hline & tebuthiuron & 34,30 & 34,54 & 42,50 & 0,73 & 0,77 & 0,72 \\
\hline & amicarbazona & 34,45 & 36,95 & 40,52 & 0,73 & 0,76 & 0,63 \\
\hline & testemunha & 37,64 & 40,00 & 41,56 & 0,74 & 0,76 & 0,69 \\
\hline & diurom + hexazinona & 34,64 & 37,83 & 41,75 & 0,72 & 0,76 & 0,69 \\
\hline \multirow[t]{6}{*}{ RB72454 (E) } & diurom + hexazinona * & 36,25 & 37,87 & 40,67 & 0,70 & 0,76 & 0,69 \\
\hline & metribuzin & 36,43 & 36,28 & 42,35 & 0,72 & 0,77 & 0,70 \\
\hline & tebuthiuron & 38,81 & 37,57 & 41,85 & 0,71 & 0,77 & 0,69 \\
\hline & amicarbazona & 37,77 & 37,76 & 40,03 & 0,73 & 0,75 & 0,64 \\
\hline & testemunha & 33,63 & 36,35 & 40,21 & 0,70 & 0,77 & 0,72 \\
\hline & diurom + hexazinona & 33,76 & 34,69 & 40,81 & 0,72 & 0,77 & 0,70 \\
\hline \multirow[t]{21}{*}{ IAC $86-2480(\mathrm{~F})$} & diurom + hexazinona * & 33,24 & 35,25 & 41,21 & 0,73 & 0,77 & 0,72 \\
\hline & metribuzin & 31,99 & 35,94 & 41,25 & 0,72 & 0,76 & 0,71 \\
\hline & tebuthiuron & 34,89 & 36,46 & 40,05 & 0,73 & 0,76 & 0,71 \\
\hline & amicarbazona & 34,20 & 36,40 & 38,72 & 0,76 & 0,77 & 0,67 \\
\hline & $\mathrm{dms}\left({ }^{2}\right)$ & 6,08 & 5,63 & 5,50 & 4,25 & 2,37 & 5,19 \\
\hline & $\mathrm{CV}(\%)$ & 8,54 & 7,81 & 6,49 & 2,84 & 1,50 & 3,65 \\
\hline & F (cult) & $7,06^{*}$ & $18,05^{*}$ & $8,02 *$ & $3,81^{*}$ & $3,05^{*}$ & $11,00^{*}$ \\
\hline & F (herb) & $0,45^{\mathrm{ns}}$ & $0,18^{\mathrm{ns}}$ & $0,92^{\mathrm{ns}}$ & $1,91^{\mathrm{ns}}$ & $0,55^{\mathrm{ns}}$ & $37,78^{*}$ \\
\hline & F (cult*herb) & $0,92^{\mathrm{ns}}$ & $1,30^{\mathrm{ns}}$ & $0,30^{\mathrm{ns}}$ & $1,83^{*}$ & $0,58^{\text {ns }}$ & $1,16^{\mathrm{ns}}$ \\
\hline & F (test vs herb em A) & $1,70^{\mathrm{ns}}$ & $5,04^{*}$ & $0,10^{\mathrm{ns}}$ & $2,53^{\mathrm{ns}}$ & $0,32^{\text {ns }}$ & $3,42^{\text {ns }}$ \\
\hline & $\mathrm{F}$ (test vs herb em B) & $0,27^{\mathrm{ns}}$ & $0,70^{\text {ns }}$ & $0,06^{\mathrm{ns}}$ & $0,02^{\text {ns }}$ & $2,15^{\mathrm{ns}}$ & $5,96^{*}$ \\
\hline & F (test vs herb em C) & $5,13^{*}$ & $0,00^{\text {ns }}$ & $0,13^{\text {ns }}$ & $0,08^{\mathrm{ns}}$ & $0,00^{\text {ns }}$ & $0,55^{\mathrm{ns}}$ \\
\hline & F (test vs herb em D) & $0,10^{\mathrm{ns}}$ & $0,21^{\mathrm{ns}}$ & $0,34^{\mathrm{ns}}$ & $0,17^{\mathrm{ns}}$ & $0,21^{\mathrm{ns}}$ & $7,01^{*}$ \\
\hline & $\mathrm{F}$ (test vs herb em E) & $0,28^{\text {ns }}$ & $2,88^{\text {ns }}$ & $0,02^{\text {ns }}$ & $3,07^{\text {ns }}$ & $0,14^{\text {ns }}$ & $0,29^{\text {ns }}$ \\
\hline & F (test vs herb em F) & $0,00^{\mathrm{ns}}$ & $0,16^{\mathrm{ns}}$ & $0,02^{\mathrm{ns}}$ & $7,02 *$ & $0,55^{\mathrm{ns}}$ & $2,56^{\mathrm{ns}}$ \\
\hline & F (entre herb A) & $0,54^{\mathrm{ns}}$ & $0,78^{\text {ns }}$ & $0,50^{\mathrm{ns}}$ & $1,91^{\mathrm{ns}}$ & $0,77^{\text {ns }}$ & $9,31 *$ \\
\hline & $\mathrm{F}$ (entre herb B) & $0,83^{\mathrm{ns}}$ & $1,09^{\mathrm{ns}}$ & $0,04^{\mathrm{ns}}$ & $2,91^{*}$ & $0,21^{\mathrm{ns}}$ & $15,37^{*}$ \\
\hline & $\mathrm{F}$ (entre herb C) & $0,99^{\text {ns }}$ & $3,08^{*}$ & $0,48^{\text {ns }}$ & $2,12^{\text {ns }}$ & $0,16^{\text {ns }}$ & $5,47^{*}$ \\
\hline & F (entre herb D) & $0,30^{\mathrm{ns}}$ & $0,42^{\text {ns }}$ & $0,71^{\mathrm{ns}}$ & $0,26^{\mathrm{ns}}$ & $0,29^{\text {ns }}$ & $9,22 *$ \\
\hline & F (entre herb E) & $1,12^{\mathrm{ns}}$ & $0,23^{\mathrm{ns}}$ & $0,51^{\mathrm{ns}}$ & $0,93^{\mathrm{ns}}$ & $1,29^{\text {ns }}$ & $3,50 *$ \\
\hline & $\mathrm{F}($ entre herb F) & $0,53^{\mathrm{ns}}$ & $0,30^{\text {ns }}$ & $0,63^{\text {ns }}$ & $1,82^{\mathrm{ns}}$ & $0,53^{\text {ns }}$ & $1,71^{\mathrm{ns}}$ \\
\hline
\end{tabular}

$\left({ }^{1}\right)$ diurom+hexazinona $\left(1170 \mathrm{~g} \mathrm{ha}^{-1}+330 \mathrm{~g} \mathrm{ha}^{-1}\right)$; diurom+hexazinona * $\left(1865 \mathrm{~g} \mathrm{ha}^{-1}+234 \mathrm{~g} \mathrm{ha}^{-1}\right)$; metribuzin $\left(2400 \mathrm{~g}^{-1}\right)$; tebuthiuron $\left(1200 \mathrm{~g} \mathrm{ha}^{-1}\right)$ e amicarbazona $\left(1260 \mathrm{~g} \mathrm{ha}^{-1}\right) \cdot\left({ }^{2}\right)$ dms = diferença mínima significativa dentro de cultivar a $5 \%$ de probabilidade; CV = coeficiente de variação. 
Tabela 4. Altura (cm) e estande (colmos m-1) das seis cultivares de cana-de-açúcar obtidas aos 30, 60, 90 e 180 DAA e aos 30, 90 e 180 DAA (dias após aplicação), respectivamente

\begin{tabular}{|c|c|c|c|c|c|c|c|c|}
\hline \multirow{3}{*}{ Cultivares } & \multirow{3}{*}{ Herbicidas $\left({ }^{1}\right)$} & \multicolumn{4}{|c|}{ Altura $(\mathrm{cm})$} & \multicolumn{3}{|c|}{ Estande $\left(\operatorname{colmos} \mathrm{m}^{-1}\right)$} \\
\hline & & \multicolumn{4}{|c|}{ Avaliações (DAA) } & \multicolumn{3}{|c|}{ Avaliações (DAA) } \\
\hline & & 30 & 60 & 90 & 180 & 30 & 90 & 180 \\
\hline \multirow{6}{*}{ IACSP94-2094 (A) } & testemunha & 22,40 & 42,77 & 69,67 & 217,58 & 10,79 & 15,58 & 15,43 \\
\hline & diurom + hexazinona & 23,20 & 51,77 & 67,72 & 218,93 & 11,64 & 16,61 & 15,58 \\
\hline & diurom + hexazinona * & 22,35 & 47,87 & 68,40 & 216,33 & 10,10 & 15,47 & 16,09 \\
\hline & metribuzin & 23,12 & 45,15 & 69,42 & 216,65 & 11,36 & 16,12 & 15,45 \\
\hline & tebuthiuron & 22,80 & 49,97 & 71,45 & 212,73 & 11,22 & 16,28 & 15,47 \\
\hline & amicarbazona & 23,40 & 44,67 & 70,60 & 218,80 & 11,42 & 15,49 & 15,18 \\
\hline \multirow{6}{*}{ IACSP94-2101(B) } & testemunha & 23,35 & 47,67 & 66,40 & 202,50 & 8,49 & 14,53 & 14,19 \\
\hline & diurom + hexazinona & 23,72 & 46,22 & 69,20 & 212,33 & 8,54 & 15,02 & 14,68 \\
\hline & diurom + hexazinona * & 24,15 & 45,20 & 65,92 & 200,70 & 7,72 & 13,01 & 14,10 \\
\hline & metribuzin & 23,82 & 46,32 & 68,82 & 201,98 & 9,26 & 14,45 & 13,57 \\
\hline & tebuthiuron & 23,52 & 46,55 & 71,37 & 204,18 & 8,54 & 13,68 & 13,85 \\
\hline & amicarbazona & 21,80 & 44,02 & 64,22 & 202,15 & 7,82 & 12,23 & 13,06 \\
\hline \multirow{6}{*}{ IACSP93-3046 (C) } & testemunha & 18,85 & 28,15 & 53,55 & 194,20 & 10,24 & 16,86 & 13,52 \\
\hline & diurom + hexazinona & 18,55 & 31,65 & 56,45 & 199,98 & 10,94 & 17,88 & 14,66 \\
\hline & diurom + hexazinona * & 17,85 & 29,35 & 57,62 & 188,80 & 9,89 & 17,49 & 13,30 \\
\hline & metribuzin & 19,05 & 29,62 & 56,25 & 192,45 & 10,36 & 18,36 & 14,68 \\
\hline & tebuthiuron & 19,32 & 28,50 & 57,02 & 190,95 & 11,02 & 18,01 & 14,23 \\
\hline & amicarbazona & 18,57 & 29,20 & 52,32 & 192,38 & 9,21 & 17,36 & 14,10 \\
\hline \multirow{6}{*}{ IACSP94-4004 (D) } & testemunha & 21,47 & 34,15 & 65,40 & 221,38 & 9,10 & 14,36 & 13,23 \\
\hline & diurom + hexazinona & 22,10 & 32,60 & 68,55 & 213,85 & 9,58 & 12,59 & 13,80 \\
\hline & diurom + hexazinona * & 25,32 & 33,27 & 65,15 & 219,38 & 10,17 & 13,67 & 14,18 \\
\hline & metribuzin & 21,55 & 36,20 & 68,75 & 213,20 & 10,12 & 15,01 & 14,61 \\
\hline & tebuthiuron & 24,52 & 34,97 & 67,97 & 216,83 & 7,90 & 12,98 & 13,35 \\
\hline & amicarbazona & 20,85 & 33,80 & 62,92 & 213,88 & 8,77 & 12,08 & 12,39 \\
\hline \multirow{6}{*}{ RB72454 (E) } & testemunha & 22,70 & 36,67 & 66,02 & 223,90 & 9,39 & 14,47 & 13,32 \\
\hline & diurom + hexazinona & 20,62 & 37,70 & 64,77 & 227,33 & 9,37 & 13,30 & 13,67 \\
\hline & diurom + hexazinona * & 20,90 & 37,27 & 66,42 & 226,88 & 8,81 & 13,70 & 13,90 \\
\hline & metribuzin & 20,25 & 40,22 & 65,42 & 220,70 & 9,26 & 14,09 & 12,37 \\
\hline & tebuthiuron & 21,97 & 40,47 & 62,80 & 226,53 & 8,92 & 13,63 & 13,69 \\
\hline & amicarbazona & 21,85 & 37,87 & 61,35 & 213,10 & 8,56 & 12,03 & 11,90 \\
\hline \multirow{23}{*}{ IAC86-2480 (F) } & testemunha & 19,35 & 31,75 & 61,67 & 202,40 & 9,94 & 16,02 & 13,71 \\
\hline & diurom + hexazinona & 18,70 & 31,85 & 56,00 & 211,98 & 9,34 & 14,64 & 13,28 \\
\hline & diurom + hexazinona * & 18,85 & 32,82 & 55,87 & 216,78 & 9,34 & 15,74 & 13,95 \\
\hline & metribuzin & 20,52 & 35,85 & 63,60 & 213,55 & 9,48 & 15,52 & 14,30 \\
\hline & tebuthiuron & 20,10 & 35,22 & 61,57 & 204,18 & 10,78 & 16,03 & 13,70 \\
\hline & amicarbazona & 20,60 & 34,65 & 59,15 & 213,60 & 10,35 & 14,86 & 13,51 \\
\hline & $\mathrm{dms}\left({ }^{2}\right)$ & 5,28 & 7,06 & 15,14 & 38,37 & 3,45 & 4,10 & 2,82 \\
\hline & CV (\%) & 11,80 & 9,00 & 11,36 & 8,73 & 17,39 & 13,30 & 9,80 \\
\hline & F (cult) & $13,41^{*}$ & $103,05^{*}$ & $12,80^{*}$ & $8,12 *$ & $7,81^{*}$ & $17,02 *$ & $8,37 *$ \\
\hline & $\mathrm{F}$ (herb) & $0,41^{\mathrm{ns}}$ & $1,87^{\mathrm{ns}}$ & $0,84^{\mathrm{ns}}$ & $0,24^{\mathrm{ns}}$ & $0,61^{\mathrm{ns}}$ & $1,76^{\mathrm{ns}}$ & $1,51^{\mathrm{ns}}$ \\
\hline & F (cult*herb) & $0,68^{\mathrm{ns}}$ & $1,13^{\text {ns }}$ & $0,33^{\text {ns }}$ & $0,22^{\mathrm{ns}}$ & $0,54^{\mathrm{ns}}$ & $0,44^{\mathrm{ns}}$ & $0,59^{\text {ns }}$ \\
\hline & $\mathrm{F}$ (test vs herb em A) & $0,17^{\mathrm{ns}}$ & $7,41^{*}$ & $0,00^{\text {ns }}$ & $0,01^{\mathrm{ns}}$ & $0,15^{\mathrm{ns}}$ & $0,14^{\mathrm{ns}}$ & $0,02^{\mathrm{ns}}$ \\
\hline & F (test vs herb em B) & $0,00^{\mathrm{ns}}$ & $1,14^{\mathrm{ns}}$ & $0,14^{\mathrm{ns}}$ & $0,05^{\mathrm{ns}}$ & $0,01^{\mathrm{ns}}$ & $0,61^{\mathrm{ns}}$ & $0,19^{\text {ns }}$ \\
\hline & F (test vs herb em C) & $0,02^{\mathrm{ns}}$ & $0,65^{\mathrm{ns}}$ & $0,36^{\mathrm{ns}}$ & $0,02^{\mathrm{ns}}$ & $0,00^{\mathrm{ns}}$ & $0,77^{\mathrm{ns}}$ & $0,83^{\mathrm{ns}}$ \\
\hline & F (test vs herb em D) & $1,01^{\mathrm{ns}}$ & $0,00^{\text {ns }}$ & $0,09^{\text {ns }}$ & $0,35^{\mathrm{ns}}$ & $0,05^{\mathrm{ns}}$ & $1,01^{\mathrm{ns}}$ & $0,34^{\mathrm{ns}}$ \\
\hline & F (test vs herb em E) & $1,30^{\mathrm{ns}}$ & $1,17^{\mathrm{ns}}$ & $0,22^{\text {ns }}$ & $0,01^{\mathrm{ns}}$ & $0,20^{\mathrm{ns}}$ & $1,04^{\mathrm{ns}}$ & $0,06^{\text {ns }}$ \\
\hline & $\mathrm{F}$ (test vs herb em F) & $0,09^{\mathrm{ns}}$ & $1,54^{\mathrm{ns}}$ & $0,37^{\mathrm{ns}}$ & $0,91^{\mathrm{ns}}$ & $0,01^{\mathrm{ns}}$ & $0,37^{\mathrm{ns}}$ & $0,00^{\text {ns }}$ \\
\hline & F (entre herb A) & $0,10^{\text {ns }}$ & $3,27^{*}$ & $0,18^{\text {ns }}$ & $0,08^{\mathrm{ns}}$ & $0,54^{\mathrm{ns}}$ & $0,26^{\mathrm{ns}}$ & $0,26^{\mathrm{ns}}$ \\
\hline & F (entre herb B) & $0,50^{\mathrm{ns}}$ & $0,39^{\text {ns }}$ & $0,61 \mathrm{~ns}$ & $0,28^{\mathrm{ns}}$ & $0,58^{\mathrm{ns}}$ & $1,26^{\mathrm{ns}}$ & $0,85^{\mathrm{ns}}$ \\
\hline & F (entre herb C) & $0,19^{\text {ns }}$ & $0,49^{\text {ns }}$ & $0,33^{\text {ns }}$ & $0,22^{\mathrm{ns}}$ & $0,84^{\mathrm{ns}}$ & $0,17^{\mathrm{ns}}$ & $0,67^{\mathrm{ns}}$ \\
\hline & F (entre herb D) & $2,23^{\mathrm{ns}}$ & $0,72^{\text {ns }}$ & $0,48^{\text {ns }}$ & $0,08^{\mathrm{ns}}$ & $1,39^{\text {ns }}$ & $1,32^{\text {ns }}$ & $1,65^{\mathrm{ns}}$ \\
\hline & F (entre herb E) & $0,34^{\mathrm{ns}}$ & $0,81^{\mathrm{ns}}$ & $0,32^{\mathrm{ns}}$ & $0,46^{\mathrm{ns}}$ & $0,16^{\mathrm{ns}}$ & $0,64^{\mathrm{ns}}$ & $1,87^{\mathrm{ns}}$ \\
\hline & $\mathrm{F}$ (entre herb F) & $0,49^{\mathrm{ns}}$ & $0,99^{\text {ns }}$ & $0,89^{\text {ns }}$ & $0,27^{\mathrm{ns}}$ & $0,65 \mathrm{~ns}$ & $0,35^{\mathrm{ns}}$ & $0,35^{\mathrm{ns}}$ \\
\hline
\end{tabular}

$\left({ }^{1}\right)$ diurom+hexazinona $\left(1170 \mathrm{~g} \mathrm{ha}^{-1}+330 \mathrm{~g} \mathrm{ha}^{-1}\right)$; diurom+hexazinona * $\left(1865 \mathrm{~g} \mathrm{ha}^{-1}+234 \mathrm{~g} \mathrm{ha}^{-1}\right)$; metribuzin $\left(2400 \mathrm{~g}\right.$ ha $\left.{ }^{-1}\right)$; tebuthiuron $\left(1200 \mathrm{~g} \mathrm{ha}^{-1}\right)$ e amicarbazona $\left(1260 \mathrm{~g} \mathrm{ha}^{-1}\right) \cdot\left({ }^{2}\right) \mathrm{dms}=$ diferença mínima significativa dentro de cultivar a 5\% de probabilidade; CV $=$ coeficiente de variação. 
Tabela 5. Qualidade tecnológica da cana-de-açúcar dada pelos teores de sólidos solúveis (SS), pureza (P), pol, açúcar redutor (AR), total recuperado (ATR), fibra e produção de colmos ( $\mathrm{t} \mathrm{ha}^{-1}$ ) em seis cultivares de cana-de-açúcar tratadas com herbicidas

\begin{tabular}{|c|c|c|c|c|c|c|c|c|}
\hline Cultivares & Herbicidas $\left({ }^{1}\right)$ & Produção & SS & $\mathrm{P}$ & Pol & $\mathrm{AR}$ & ATR & $\mathrm{F}$ \\
\hline \multirow{7}{*}{ IACSP94-2094 (A) } & & $\mathrm{t} \mathrm{ha}^{-1}$ & ${ }^{\circ}$ Brix & & 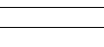 & $-\%$ & & \\
\hline & testemunha & 72,06 & 17,85 & 85,50 & 13,20 & 0,61 & 127,69 & 10,80 \\
\hline & diurom + hexazinona & 79,52 & 17,43 & 85,41 & 12,91 & 0,61 & 125,05 & 10,64 \\
\hline & diurom + hexazinona * & 78,00 & 17,01 & 84,93 & 12,52 & 0,63 & 121,57 & 10,64 \\
\hline & metribuzin & 68,67 & 17,76 & 83,90 & 12,91 & 0,66 & 125,47 & 10,67 \\
\hline & tebuthiuron & 74,02 & 17,81 & 84,29 & 13,12 & 0,65 & 127,33 & 10,20 \\
\hline & amicarbazona & 72,70 & 17,97 & 84,81 & 13,25 & 0,63 & 128,39 & 10,48 \\
\hline \multirow{6}{*}{ IACSP94-2101(B) } & testemunha & 74,47 & 18,31 & 85,89 & 13,68 & 0,60 & 132,05 & 10,47 \\
\hline & diurom + hexazinona & 76,07 & 17,97 & 85,95 & 13,33 & 0,59 & 128,75 & 10,94 \\
\hline & diurom + hexazinona * & 77,51 & 17,86 & 84,20 & 13,12 & 0,65 & 127,31 & 10,28 \\
\hline & metribuzin & 73,64 & 18,20 & 85,03 & 13,39 & 0,62 & 129,56 & 10,77 \\
\hline & tebuthiuron & 77,05 & 18,03 & 86,07 & 13,42 & 0,59 & 129,54 & 10,78 \\
\hline & amicarbazona & 66,33 & 17,22 & 83,77 & 12,44 & 0,66 & 121,11 & 11,02 \\
\hline \multirow{6}{*}{ IACSP93-3046(C) } & testemunha & 72,47 & 17,14 & 82,59 & 12,20 & 0,69 & 119,73 & 10,75 \\
\hline & diurom + hexazinona & 83,39 & 17,92 & 84,40 & 13,08 & 0,64 & 126,91 & 10,81 \\
\hline & diurom + hexazinona $*$ & 72,13 & 17,71 & 83,25 & 12,60 & 0,67 & 122,66 & 11,51 \\
\hline & metribuzin & 82,50 & 18,26 & 84,70 & 13,36 & 0,63 & 129,39 & 10,85 \\
\hline & tebuthiuron & 84,43 & 17,64 & 84,24 & 12,96 & 0,65 & 125,83 & 10,35 \\
\hline & amicarbazona & 78,22 & 17,19 & 83,49 & 12,46 & 0,67 & 121,42 & 10,59 \\
\hline \multirow{6}{*}{ IACSP94-4004 (D) } & testemunha & 92,83 & 15,64 & 82,14 & 11,14 & 0,71 & 109,48 & 10,76 \\
\hline & diurom + hexazinona & 87,50 & 16,41 & 80,10 & 11,56 & 0,78 & 113,99 & 9,91 \\
\hline & diurom + hexazinona $*$ & 93,07 & 16,22 & 78,90 & 11,31 & 0,82 & 112,02 & 9,97 \\
\hline & metribuzin & 95,03 & 15,17 & 78,37 & 10,58 & 0,84 & 105,49 & 9,41 \\
\hline & tebuthiuron & 81,67 & 16,11 & 78,43 & 11,18 & 0,83 & 110,94 & 10,04 \\
\hline & amicarbazona & 76,34 & 15,37 & 80,32 & 10,93 & 0,78 & 108,19 & 9,73 \\
\hline \multirow{6}{*}{ RB72454 (E) } & testemunha & 73,30 & 17,12 & 82,97 & 12,46 & 0,69 & 121,57 & 9,93 \\
\hline & diurom + hexazinona & 83,61 & 18,03 & 86,18 & 13,55 & 0,59 & 130,84 & 10,28 \\
\hline & diurom + hexazinona $*$ & 82,74 & 17,69 & 84,76 & 13,13 & 0,64 & 127,27 & 10,22 \\
\hline & metribuzin & 63,01 & 17,10 & 83,54 & 12,47 & 0,67 & 121,48 & 10,55 \\
\hline & tebuthiuron & 78,55 & 17,56 & 83,11 & 12,68 & 0,68 & 123,51 & 10,70 \\
\hline & amicarbazona & 73,16 & 17,55 & 84,83 & 12,90 & 0,63 & 125,09 & 10,78 \\
\hline \multirow{23}{*}{ IAC $86-2480(\mathrm{~F})$} & testemunha & 80,64 & 17,60 & 83,66 & 12,72 & 0,66 & 123,71 & 10,89 \\
\hline & diurom + hexazinona & 75,39 & 16,71 & 81,65 & 11,89 & 0,73 & 116,63 & 10,33 \\
\hline & diurom + hexazinona $*$ & 75,69 & 17,31 & 83,20 & 12,39 & 0,67 & 120,76 & 11,13 \\
\hline & metribuzin & 78,43 & 17,49 & 82,67 & 12,51 & 0,69 & 122,02 & 10,78 \\
\hline & tebuthiuron & 75,89 & 17,02 & 82,85 & 12,25 & 0,69 & 119,65 & 10,62 \\
\hline & amicarbazona & 77,19 & 16,37 & 81,38 & 11,60 & 0,74 & 113,99 & 10,42 \\
\hline & $\mathrm{dms}\left({ }^{2}\right)$ & 30,00 & 2,88 & 7,37 & 2,85 & 0,22 & 24,62 & 1,42 \\
\hline & CV (\%) & 20,78 & 8,12 & 4,29 & 11,04 & 16,34 & 9,79 & 6,55 \\
\hline & F (cult) & $2,39 *$ & $7,09^{*}$ & $7,56^{*}$ & $7,42 *$ & $7,86^{*}$ & $7,25^{*}$ & $4,73^{*}$ \\
\hline & $\mathrm{F}$ (herb) & $0,54^{\mathrm{ns}}$ & $0,34^{\mathrm{ns}}$ & $0,29^{\text {ns }}$ & $0,29^{\mathrm{ns}}$ & $0,29^{\text {ns }}$ & $0,30^{\mathrm{ns}}$ & $0,24^{\text {ns }}$ \\
\hline & F (cult*herb) & $0,44^{\mathrm{ns}}$ & $0,37^{\mathrm{ns}}$ & $0,35^{\mathrm{ns}}$ & $0,31^{\mathrm{ns}}$ & $0,36^{\mathrm{ns}}$ & $0,32^{\mathrm{ns}}$ & $1,08^{\text {ns }}$ \\
\hline & $\mathrm{F}$ (test vs herb em A) & $0,08^{\mathrm{ns}}$ & $0,11^{\mathrm{ns}}$ & $0,18^{\mathrm{ns}}$ & $0,12^{\mathrm{ns}}$ & $0,20^{\mathrm{ns}}$ & $0,11^{\mathrm{ns}}$ & $0,53^{\text {ns }}$ \\
\hline & $\mathrm{F}$ (test vs herb em B) & $0,00^{\mathrm{ns}}$ & $0,35^{\mathrm{ns}}$ & $0,21^{\mathrm{ns}}$ & $0,51^{\mathrm{ns}}$ & $0,17^{\mathrm{ns}}$ & $0,54^{\mathrm{ns}}$ & $0,57^{\text {ns }}$ \\
\hline & F (test vs herb em C) & $0,75^{\mathrm{ns}}$ & $0,61^{\mathrm{ns}}$ & $0,53^{\mathrm{ns}}$ & $0,70^{\mathrm{ns}}$ & $0,47^{\mathrm{ns}}$ & $0,71^{\mathrm{ns}}$ & $0,03^{\text {ns }}$ \\
\hline & F (test vs herb em D) & $0,47^{\mathrm{ns}}$ & $0,08^{\text {ns }}$ & $2,21^{\mathrm{ns}}$ & $0,00^{\mathrm{ns}}$ & $2,76^{\mathrm{ns}}$ & $0,01^{\mathrm{ns}}$ & $6,31 *$ \\
\hline & F (test vs herb em E) & $0,11^{\mathrm{ns}}$ & $0,37^{\text {ns }}$ & $0,59^{\text {ns }}$ & $0,42^{\mathrm{ns}}$ & $0,69^{\text {ns }}$ & $0,39^{\text {ns }}$ & $2,30^{\text {ns }}$ \\
\hline & F (test vs herb em F) & $0,21^{\mathrm{ns}}$ & $0,64^{\mathrm{ns}}$ & $0,45^{\mathrm{ns}}$ & $0,61^{\mathrm{ns}}$ & $0,43^{\mathrm{ns}}$ & $0,61^{\mathrm{ns}}$ & $0,36^{\text {ns }}$ \\
\hline & F (entre herb A) & $0,31^{\mathrm{ns}}$ & $0,32^{\mathrm{ns}}$ & $0,10^{\mathrm{ns}}$ & $0,16^{\mathrm{ns}}$ & $0,09^{\mathrm{ns}}$ & $0,19^{\text {ns }}$ & $0,48^{\mathrm{ns}}$ \\
\hline & F (entre herb B) & $0,35^{\mathrm{ns}}$ & $0,32^{\mathrm{ns}}$ & $0,30^{\mathrm{ns}}$ & $0,35^{\mathrm{ns}}$ & $0,29^{\mathrm{ns}}$ & $0,36^{\mathrm{ns}}$ & $1,04^{\text {ns }}$ \\
\hline & F (entre herb C) & $0,42^{\mathrm{ns}}$ & $0,35^{\mathrm{ns}}$ & $0,11^{\mathrm{ns}}$ & $0,28^{\mathrm{ns}}$ & $0,08^{\mathrm{ns}}$ & $0,30^{\mathrm{ns}}$ & $2,31^{\mathrm{ns}}$ \\
\hline & F (entre herb D) & $1,01^{\mathrm{ns}}$ & $0,68^{\mathrm{ns}}$ & $0,24^{\mathrm{ns}}$ & $0,29^{\mathrm{ns}}$ & $0,26^{\mathrm{ns}}$ & $0,32^{\mathrm{ns}}$ & $0,79^{\text {ns }}$ \\
\hline & F (entre herb E) & $1,19^{\mathrm{ns}}$ & $0,25^{\mathrm{ns}}$ & $0,42^{\mathrm{ns}}$ & $0,37^{\mathrm{ns}}$ & $0,36^{\mathrm{ns}}$ & $0,37^{\mathrm{ns}}$ & $0,77^{\mathrm{ns}}$ \\
\hline & F (entre herb F) & $0,03^{\mathrm{ns}}$ & $0,46^{\mathrm{ns}}$ & $0,18^{\mathrm{ns}}$ & $0,30^{\mathrm{ns}}$ & $0,22^{\mathrm{ns}}$ & $0,30^{\mathrm{ns}}$ & $1,24^{\mathrm{ns}}$ \\
\hline
\end{tabular}

( $\left.{ }^{1}\right)$ diurom+hexazinona (1170 $\left.\mathrm{g} \mathrm{ha}^{-1}+330 \mathrm{~g} \mathrm{ha}^{-1}\right)$; diurom+hexazinona * $\left(1865 \mathrm{~g} \mathrm{ha}^{-1}+234 \mathrm{~g} \mathrm{ha}^{-1}\right)$; metribuzin $\left(2400 \mathrm{~g}\right.$ ha $\left.{ }^{-1}\right)$; tebuthiuron $\left(1200 \mathrm{~g} \mathrm{ha}^{-1}\right)$ e amicarbazona $\left(1260 \mathrm{~g} \mathrm{ha}^{-1}\right) .\left({ }^{2}\right) \mathrm{dms}=$ diferença mínima significativa dentro de cultivar a $5 \%$ de probabilidade; CV = coeficiente de variação. 
No estudo, os autores verificaram que tanto a produção quanto a qualidade da cana não foram afetadas pelos herbicidas e que as diferenças observadas no estudo foram devidas às diferentes características das cultivares e não ao produto ou doses utilizadas.

\section{CONCLUSÕES}

1. As cultivares IACSP94-2094, IACSP94-2101, IACSP93-3046, IACSP94-4004, RB72454 e IAC86-2480 não são afetadas pelos herbicidas, apenas revelam diferenças inerentes à própria genética.

2. Em todas as cultivares, observam-se apenas leves sintomas de intoxicação na fase inicial de desenvolvimento e não se constatou nenhum prejuízo ao conteúdo de clorofila.

3. No sistema fotossintético há pequeno prejuízo na fase inicial, quando avaliado pela eficiência fitoquímica máxima do FS II $\left(\mathrm{F}_{\mathrm{v}} / \mathrm{F}_{\mathrm{m}}\right)$, mas que não é suficiente para prejudicar altura, estande, produção e qualidade tecnológica das diferentes cultivares de cana-de-açúcar estudadas.

\section{AGRADECIMENTOS}

Ao Pesquisador Dr. Marcos G.A. Landell (Centro de Cana, IAC) pelo apoio em infraestrutura; Ao Prof. Dr. Pedro Luis da Costa Aguiar Alves (UNESP/ FCAV/Jaboticabal) pelo empréstimo do clorofilômetro e fluorômetro; ao Dorival Rodrigues, técnico de Apoio do Centro de Cana do IAC, pela contribuição na realização da pesquisa e à Coordenação de Aperfeiçoamento de Pessoal de Nível Superior (CAPES) pela concessão da bolsa de estudos à primeira autora.

\section{REFERÊNCIAS}

AZANIA, C.A.M.; CASAGRANDE, A.A.; ROLIM, J.C. Seletividade de imazapic às soqueiras de cana-de-açúcar (Saccharum spp.). Planta Daninha, v.19, p.345-350, 2001.

AZANIA, C.A.M.; AZANIA, A.A.M. Caderno Técnico: Invasoras: menos invasoras, mais dinheiro. Cana Cultivar, v.79, p. 3-10, 2005.

AZANIA, C.A.M.; ROLIM, J.C.; CASAGRANDE, A.A.; LAVORENTI, N.A.; AZANIA, A.A.P.M. Seletividade de herbicidas. I - Utilização do método de testemunhas pareadas em experimento com cana-de-açúcar. Planta Daninha, v.23, p.661-667, 2005a.

AZANIA, C.A.M.; ROLIM, J.C.; CASAGRANDE, A.A.; LAVORENTI, N.A.; AZANIA, A.A.P.M. Seletividade de herbicidas. II - Aplicação de herbicidas em pós-emergência inicial e tardia da cana-de-açúcar na época das chuvas. Planta Daninha, v.23, p.669-675, 2005b.
AZANIA, C.A.M.; ROLIM, J.C.; CASAGRANDE, A.A.; LAVORENTI, N.A.; AZANIA, A. A.P.M. Seletividade de herbicidas. III - Aplicação de herbicidas em pós-emergência inicial e tardia da cana-de-açúcar na época da estiagem. Planta Daninha, v.24, p.489-495, 2006.

AZANIA, C.A.M.; ROLIM, J.C.; AZANIA, A.A.P.M.; SCHIAVETTO, A.R.; VANZELA, I.P. Seletividade de herbicidas em cana-de-açúcar. Energia Brasileira, ano II, n.17, p.56-60, 2008.

BARELA, J.F.; CHRISTOFFOLETI, P.J. Seletividade de herbicidas aplicados em pré-emergência da cultura da canade-açúcar (RB867515) tratada com nematicidas. Planta Daninha, v.24, p.371-378, 2006.

CARBONARI, C.A. Eficácia do herbicida amicarbazone em aplicação conjunta com a colheita de cana-de-açúcar no controle das principais plantas daninhas da cultura. Botucatu, 2007. 119 f. Dissertação (Mestrado) - Universidade Estadual Paulista, Faculdade de Ciências Agronômicas, Botucatu.

CATUNDA, M.G.: FREITAS, S.P.; OLIVEIRA, J.G.; SILVA, C.M.M. Efeitos de herbicidas na atividade fotossintética e no crescimento de abacaxi (Ananas comossus). Planta Daninha, v.23, p.115-121, 2005.

CECHIN, I. Uso de sistemas portáteis de fluorescência na avaliação do estresse. In: CONGRESSO DA SOCIEDADE BOTÂNICA DE SÃO PAULO, 20., 1996, São Carlos, SP, Anais... São Carlos: Universidade Federal de São Carlos, 1996, p.1-28.

CHRISTOFFOLETI, P.J. Resistência de plantas daninhas aos herbicidas. In: I SIMPÓSIO SOBRE HERBICIDAS E PLANTAS DANINHAS, Dourados. Resumos... 1997. p.75-97.

CONSECANA: Manual de Instruções. 5. Ed., Piracicaba, SP, 2006. p.48-53. Disponível em: htt: www.unica.com.br/ publicaçoes. Acesso em: 18.7.2008.

FAGLIARI, J.R.; OLIVEIRA JÚNIOR, R.S.; CONSTANTIN, J. Métodos de avaliação da seletividade de herbicidas para a cultura da cana-de-açúcar (Saccharum spp.) Acta Scientiarum Agronomy, v.23, p.1229-1234, 2001.

FERREIRA, E.A.; SANTOS, J.B.; SILVA, A.A.; VENTRELLA, M.C.; BARBOSA, M.H.P.; PROCÓPIO, S.O.; REBELLO, V.P.A. Sensibilidade de cultivares de cana-de-açúcar à mistura trifloxysulfuron-sodium + ametryn. Planta Daninha, v.23, p.93-99, 2005.

GRACIANO, P.A.; RAMALHO, J. F. G. P. Efeito da matoinfestação na cultura da cana-de-açúcar. Stab: Açúcar, Álcool e Subproduto, v.1, p.22-24, 1983.

LANDELL, M.G.A.; CAMPANA, M.P.; RODRIGUES, A.A.; CRUZ, G.M.; BATISTA, L.A.R.; FIGUEIREDO, P.;SILVA, M.A.; BIDOIA, M.A.P.; ROSSETO, R.; MARTINS, A.L.M.; GALLO, P.B.; KANTHACK, R.A.D.; CAVICHIOLI, J.C.; VASCONCELOS, A.C.M.; XAVIER, M.A. A variedade IAC86-2480 como nova opção de cana-de-açúcar para fins forrageiros: Manejo de produção e uso na alimentação animal. Campinas: Instituto Agronômico. 2002. 36p. (Boletim Técnico, 193) 
LANDELL, M.G.A.; CAMPANA, M.P.; FIGUEIREDO, P.; VASCONCELOS, A.C.M.; XAVIER, M.A.; BIDOIA, M.A. P.; PRADO, H.; SILVA, M.A.; DINARDO-MIRANDA, L.L.; SANTOS, A.S.; PERECIN, D.; ROSSETO, R.; SILVA, D.S.; MARTINS, A.L.M.; GALLO, P.B.; KANTHACK, R.A.D.; CAVICHIOLI, J.C.; VEIGA FILHO, A.A.; ANJOS, I.A.; AZANIA, C.A.M.; PINTO, L.R.; SOUZA, S.A.C.D. Variedades de canade-açúcar para o Centro-Sul do Brasil. Campinas: Instituto Agronômico. 2005. 33p. (Boletim Técnico, 197)

MACIEL, C.D.G.; VELINI, E. D.; CONSTANTIN, J.; JARDIM, C.E.; BERNARDO, R.S.; FONSECA, P.P.M.; BARELA, J.D.; OLIVEIRA, J.S. Eficiência e seletividade dos herbicidas trifloxysulfuron-sodium+ametrine e hexazinone+diuron em função da tecnologia de aplicação e do manejo mecânico da palha de cana-de-açúcar na linha de plantio. Planta Daninha, v.26, p.665-676, 2008.

MAPA: Ministério da Agricultura, Pecuária e Abastecimento. Sistema de agrotóxicos fitossánitarios. Disponível em: < http:/ /www. extranet.agricultura.gov.br/agrofit_cons/ principal_agrofit_const.com.br>. Acesso em: 10 jan. 2009.

NEGRISOLI, E.; VELINI, E.D.; TOFOLI, G.R.; CAVENAGHI, A.L.; MARTINS, D.; MORELLI, J.L. ;COSTA, A.G.F. Seletividade de herbicidas aplicados em pré-emergência na cultura de canade-açúcar tratada com nematicidas. Planta Daninha, v.22, p.567$575,2004$.

OLIVEIRA JUNIOR, R.S. Mecanismos de ação de herbicidas. In: OLIVEIRA JUNIOR, R. S.; CONSTATIN J. (Org.). Plantas daninhas e seu manejo. Guaíba: Livraria e Editora Agropecuária, 2001ª p.207-260.

OLIVEIRA JUNIOR, R.S. Seletividade de herbicidas para culturas e plantas daninhas. In: OLIVEIRA JUNIOR, R.S..; CONSTATIN, J. (Org.). Plantas daninhas e seu manejo. Guaíba: Livraria e Editora Agropecuária, 2001b. p.291-314.

PIMENTEL GOMES, F. Curso de Estatística experimental. 14.ed. Piracicaba: Degaspari, 2000. 477p.

RIBEIRO, R.V.; SANTOS, M.G.; SOUZA, G.M.; MACHADO, E.C.; OLIVEIRA, R.F.; ANGELOCCI, L.R.; PIMENTEL, C. Environmental effects on photosynthetic capacity of bean genotypes. Pesquisa Agropecuária Brasileira, v.39, p.615623, 2004.

RODRIGUES, B.N.; ALMEIDA, F.S. In: Guia de herbicidas. 5 ed. Londrina, 2005.

ROLIM, J.C.; CHISTOFFOLETI, P.J. Tolerância de variedades de cana-de-açúcar ao herbicida tebuthiuron. Piracicaba: IAAPlanalsucar, 1982, p.1-21.

SALLA, L.; RODRIGUES, J.C.; MARENCO, R.A. Teores de clorofila em árvores tropicais determinados com o SPAD502. Revista Brasileira de Biociências, v.5, supl.2, p.159$161,2007$.

ÚNICA: Portal do agronegócio: Safra de cana-de-açúcar 2008/ 09. p.5, 2007, 12p. Disponível em: htt: www.portaldoagronegócio.com.br. Acesso em: 30.4.2008.
VELINI, E.D. ; FREDERICO, L.A.; MORELLI, J.L.; KOJIMA, K. Avaliação dos efeitos do herbicida clomazone, aplicado em pós-emergência, sobre o crescimento e produtividade de soqueiras de nove cultivares de cana-de-açúcar. In: CONGRESSO NACIONAL DOS TÉCNICOS AÇUCAREIROS E ALCOOLEIROS DO BRASIL - STAB, 1993, Águas de São Pedro, SP. Anais... Águas de São Pedro: STAB, 1993, p.125-128.

VELINI, E.D.; MARTINS, D.; MANOEL, L.A.; MATSUOKA, S.; TRAVAIN, J.C.; CARVALHO, J.C. Avaliação da seletividade da mistura de oxyfluorfen e ametryne, aplicada em pré e pósemergência, a dez variedades de cana-de-açúcar (cana planta). Planta Daninha, v.18, p.123-134, 2000. 